\title{
METODE UNTUK MENENTUKAN JEJARI YARN $r$ PADA MESIN PINTAL OPEN END ROTOR SPINNING MELALUI PENDEKATAN TEORITIK DAN KAJIAN FISIKA
}

\author{
Oleh: Valentinus GalihVidiaPutra ${ }^{[1]}$, M.F. Rosyid ${ }^{[2]}$ \\ ${ }^{[1]}$ StafpengajarSekolahTinggiTeknologiTekstil, Bandung \\ ${ }^{[2]}$ UniversitasGadjahMada, Yogyakarta \\ Email: galih_vidia@yahoo.com
}

\begin{abstract}
INTISARI
Penentuan jejari yarn $r$ dalam industri tekstil umumnya sulit dilakukan karena adanya keterbatasan alat, seperti alat ukur dalam skala mikroskopik. Pada penelitian ini jejari yarn $r$ dapat ditentukan dari nilai twist pada yarn. Penentuan twist pada yarn dapat diselesaikankan dengan berbagai teori pemodelan untuk menentukan hubungan antara twist pada proses spinning dengan kecepatan delivery yarn dan kecepatan rotor. Pada penelitian ini telah dijabarkan perumusan yang dapat memperlihatkan hubungan antara twist terhadap jejari yarn dengan menggunakan pendekatan teoritik secara lebih lengkap.
\end{abstract}

\begin{abstract}
Calculating the yarn radius $r$ can be derived by knowing the twist of yarn. Theoretical consideration for a modeling the relationship of twist in rotor spinning has been done and will be developed to get a good model to show the twist. In this research, the formula has been verified and investigated to show the relationship of twist and yarn radius completely by theoretical approach
\end{abstract}

keyword: jejari yarn $r$,open end rotor spinning, mesinpintaltekstil

\section{I.PENDAHULUAN}

Twist dikarakteristikkan berdasarkan arah dan kecepatan rotasi pada rotor dan juga kecepatan pada penghantar yarn. Definisi dari twist adalah banyaknya lilitan pada yarn tiap satuan panjang dan memiliki dimensi $[\mathrm{L}]^{-1}$. Proses twist pada mesin spinning dapat dilakukan dengan open end spinning ( rotor spinning, friction spinning dan air jet spinning). Menurut Furter (2009) ${ }^{[1]}$ dan. Lawrence ( $2010)^{[2]}$ besar twist pada mesin spinning bergantung pada kecepatan rotor pada mesin rotor spinning dan juga kecepatan delivery yarn, dan dirumuskan seperti pada persamaan (1) di bawah, sedangkan menurut Vaclav Rohlena (1975) ${ }^{[3]}$ bentuk twist dapat dibedakan menjadi dua buah bentuk yaitu: tipe Z-Twisted dan tipe S-Twisted. Bentuk STwisted adalah bentuk yang mana arah kecepatan antara penghantar yarn dan kecepatan rotor memiliki arah yang sama, sebaliknya jika arahnya berlawanan, maka tipe twist adalah Z-Twisted, besar twist didapatkan melalui perbandingan antara kecepatan sudut yarn terhadap kecepatan delivery yarn, secara garis besar rumusan untuk Z-twist adalah sesuai persamaan (2)

$$
\begin{gathered}
T=\frac{n_{\text {rotor }}}{V d}(1 / m) \\
T=\frac{1}{\eta \pi d}+\frac{n_{\text {rotor }}}{V d} \approx \frac{n_{\text {rotor }}}{V d}(1 / m)
\end{gathered}
$$

Dengan $\eta$ adalah koefisien penyusutan dengan nilai $\eta<1$ dan umumnyaberkisar $0.95 \ldots 0,99 ; d$ adalah diameter rotor; $n_{\text {rotor }}$ adalah kecepatan anguler rotor tiap satu putaran dalam satuan waktu; dan $V d$ adalah kecepatan delivery yarn. Hubungan twist terhadap

Fisika-Universitas Negerí semarang 190 
kecepatan rotor $\left(n_{\text {rotor }}\right)$ dan delivery yarn $(V d)$ menurut Gunter Trommer (1995) ${ }^{[4]}$ pada mesin rotor spinning adalah sesuai dengan persamaan (3)

$$
T=\left(\frac{n_{\text {rotor }}}{V d}+\frac{1000}{\pi d}+e_{G} \frac{1000}{\pi d}\right) \approx \frac{n_{\text {rotor }}}{V d}
$$

\section{$(1 / \mathrm{m})$}

Pada ketiga persamaan di atas menunjukkan terdapat kesamaan bahwa untuk pengabaian nilai koefisien penyusutan $\eta$ dan konstanta yang dikarenakan pengaruh perputaran yarn terhadap rotor $e_{G}$, makadidapatkan hasil persamaan (1). Pada persamaan (2) dan persamaan (3) ( kedua persamaan tersebut disebut sebagai actual twist, yaitu besar twist yang terukur secara real ) terdapat berbagai macam pemodelan untuk menentukan besar twist. Dari rumusan (2) dan (3) terdapat suatu perbedaan rumusan dalam menentukan nilai twist jika factor koefisien penyusutan $\eta$ dan konstanta yang dikarenakan pengaruh perputaran yarn terhadap rotor $e_{G}$ tidakdiabaikan.

\section{PEMODELAN TWIST}

Pada tipe Z-Twisted dapat dianalisa sebagai berikut di bawah:

Jika dimisalkan bahwa rotor bergerak dengan suatu kecepatan sudut $\phi^{\prime}$ dan yarn bergerak dengan kecepatan $\psi^{\prime}$ dengan arah gerak yang sama seperti pada Gambar-1,maka dapatdiperlihatkan bahwa jika yarn dan rotor dianggap sebagai suatu silinder pejal dengan massa $\mathrm{m}$ dan $\mathrm{M}$, dengan jejari yarn adalah $r$ sedangkan jejari rotor adalah $\mathrm{R}$.
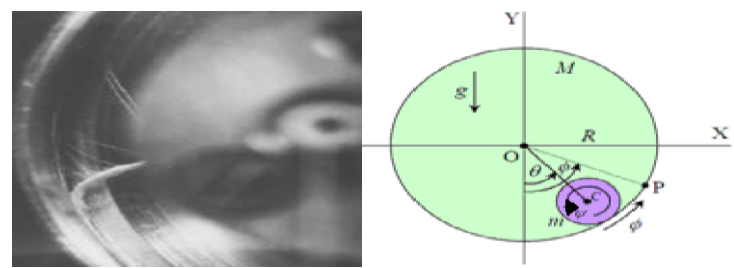

Gambar-1. Skema pergerakan mesin spinning dan yarn

$$
\begin{gathered}
(R-r) \theta^{\prime}=\psi^{\prime} r+R \phi^{\prime}=V d+R \phi^{\prime} \\
V d=(R-r) \theta^{\prime}-R \phi^{\prime}
\end{gathered}
$$

Jika panjang jejari $r<<\mathrm{R}$ maka nilai $(R-r) \cong R$, maka dapat dituliskan

$$
V d=\left(\theta^{\prime}-\phi^{\prime}\right) R
$$

$$
\begin{aligned}
& V d=\left(n_{\text {yarn }}-n_{\text {rotor }}\right) \frac{\lambda \pi}{180^{0}} R \\
& V d=\frac{\left(n_{\text {yarn }}-n_{\text {rotor }}\right)}{360^{0}} \lambda \pi d
\end{aligned}
$$

Keterangan:

$\mathrm{Vd}=$ kecepatan pengantar yarn $(\mathrm{m} / \mathrm{s})$

$n_{\text {yarn }}, n_{\text {rotor }}=$ kecepatan yarn dan kecepatan rotor

dalam setiap sudut $\lambda(1 / \mathrm{s})$

$\mathrm{R}=$ jejari rotor $(\mathrm{m})$

$d=$ diameter rotor $(\mathrm{m})$

Jika untuk satu putaran penuh Persamaan (7) dapat dituliskan menjadi

$$
\begin{aligned}
& V d=\left(n_{\text {yarn }}-n_{\text {rotor }}\right) \pi d \\
& T=\frac{n_{\text {yarn }}}{V d}=\frac{1}{\pi d}+\frac{n_{\text {rotor }}}{V d}
\end{aligned}
$$

dapat dilakukan pendekatan bahwa besar twist $\mathrm{T}$ adalah

$$
T=\frac{n_{\text {yarn }}}{V d} \approx \frac{n_{\text {rotor }}}{V d}
$$

Keterangan:

$T=$ twist $(1 / \mathrm{m})$

Jika jejari yarn $r$ memiliki nilai yang cukup besar, maka dapat dimodelkan bahwa bentuk persamaan (4) adalah

$$
\begin{aligned}
& (R-r) \theta^{\prime}=\psi^{\prime} r+R \phi^{\prime}=V d+R \phi^{\prime} \\
& (R-r) \frac{\lambda \pi}{180} n_{\text {yarn }}=V d+R \frac{\lambda \pi}{180} n_{\text {rotor }} \\
& 2(R-r) \pi n_{\text {yarn }}=V d+2 R . \pi n_{\text {rotor }} \\
& 2 V_{\text {Galih }} R \pi n_{\text {yarn }}=V d+2 R \pi \cdot n_{\text {rotor }} \\
& n_{\text {yarn }}=\frac{V d+d \pi n_{\text {rotor }}}{V_{\text {Galih }} d \pi}=\frac{V d}{V_{\text {Galih }} d \pi}+\frac{n_{\text {rotor }}}{V_{\text {Galih }}} \\
& T=\frac{n_{\text {yarn }}}{V d} \cong\left(\frac{1}{V_{\text {Galih }}{ }^{\pi d}}+\frac{n_{\text {rotor }}}{V d}\right)(\text { d dalam } \\
& \text { meter) } \\
& R-r=V_{\text {Galih }} R \\
& r=R-\frac{d V_{\text {Galih }}}{2}
\end{aligned}
$$

$V_{\text {Galih }}$ adalah suatu konstanta yang bergantung dari jejari yarn dan jejari rotor dan besarnya sekitar 0.99 semisal untuk nilai jejari rotor $\mathrm{R}=33 \mathrm{~mm}$ dan $\mathrm{r}$ $=0.10 \mathrm{~mm}$ pada bahan katun (Gunter Trommer, 1995) ${ }^{[4]}$. Pada persamaan (17) dapat pula dijabarkan ke dalam bentuk persamaan lain, yaitu 


$$
\begin{gathered}
n_{\text {yarn }}=n_{\text {rotor }}+\frac{V d}{\pi 2 R}+\frac{V d}{\pi 2 R}\left(\frac{r}{R}\right)+n_{\text {rotor }}\left(\frac{r}{R}\right) \\
n_{\text {yarn }}=n_{\text {rotor }}+\frac{V d}{\pi d}+\left(\frac{r}{R}\right) n_{\text {rotor }}+\left(\frac{r}{R}\right) \frac{V d}{\pi d}= \\
\left(n_{k}+\frac{V d}{\pi d}\right)+\left(G_{\text {Vidia }} n_{k}+G_{\text {Vidia }} \frac{V d}{\pi d}\right)
\end{gathered}
$$

$G_{\text {Vidia }}$ adalah konstanta perbandingan jejari yarn dengan jejari rotor. Umumnya nilai $G_{V i d i a}$ berkisar 0.003. untuk nilai jejari rotor $\mathrm{R}=33 \mathrm{~mm}$ dan $\mathrm{r}=0.1$ mm pada bahan katun. Umumnya nilai dari Ztwisted dapat diambil pendekatan dengan mengabaikan besar kecepatan sudut yang dimunculkan oleh $G_{\text {Vidia }} n_{\text {rotor }}$, sehingga persamaan (20) dapat dituliskan menjadi

$$
n_{\text {yarn }} \cong n_{\text {rotor }}+\frac{V d}{\pi d}+G_{\text {Vidia }} \frac{V d}{\pi d}
$$

Maka besar twist $T$ secara lengkap adalah

$$
\begin{gathered}
T=\frac{n_{\text {yarn }}}{V d}= \\
\frac{1}{V d}\left(n_{\text {rotor }}+\frac{V d}{\pi d}+G_{\text {Vidia }} \frac{\text { Vd }}{\pi d}+G_{\text {Vidid }} n_{\text {rotor }}\right) \\
\mathrm{T}=\left(\frac{n_{\text {rotor }}}{V_{d}}+\frac{1}{\pi d}+G_{\text {Vidia }} \frac{1}{\pi d}+G_{\text {Vidia }} \frac{n_{\text {rotor }}}{\text { Vd }}\right) \\
T \cong\left(\frac{n_{\text {rotor }}}{V d}+\frac{1}{\pi d}+G_{\text {Vidia }} \frac{1}{\pi d}\right)(\text { untuk d } \\
T \cong\left(\frac{n_{\text {rotor }}}{V d}+\frac{1000}{\pi d}+G_{\text {Vidia }} \frac{1000}{\pi d}\right) \text { (untuk } \\
d \text { dalam milimeter) }
\end{gathered}
$$

Persamaan (16) dan persamaan (23) dapat dilakukan aproksimasi menjadi

$$
\begin{aligned}
& T=\frac{1}{V_{\text {Galih }} \pi d}+\frac{n_{\text {rotor }}}{V d}\left(1+G_{\text {vidia }}\right) \approx \frac{n_{\text {rotor }}}{V d} \\
& T=\left(\frac{n_{\text {rotor }}}{V d}+\frac{1}{\pi d}+G_{\text {Vidia }}\left(\frac{1}{\pi d}+\frac{n_{\text {rotor }}}{V d}\right)\right)
\end{aligned}
$$

\section{HASIL DAN PEMBAHASAN}

Persamaan (16) dan (25) adalah persamaan yang memiliki bentuk rumusan yang sama dengan persamaan (2) dan persamaan (3). Jika dibandingkan persamaan (16) dengan persamaan (2), maka dapat ditentukan bahwa koefisien penyusutan $\eta$ pada twist bergantung pada nilai konstanta $\mathrm{V}_{\text {Galih, yang besarnya dapat ditentukan }}$ dari persamaan (17). Persamaan (25) dapat dibandingkan dengan persamaan (3), sehingga dapat ditentukan bahwa nilai koefisien $e_{G}$ memiliki kesebandingan dengan nilai $\mathrm{G}_{\text {Vidia }}$. Menurut Vaclav rohlena $(1975)^{[3]}$, besar koefisien penyusutan $\eta<1$ dan besar nilai $\eta \approx 0.95$. Pada penelitian ini didapatkan bahwa besar $\mathrm{V}_{\text {Galih }}<1$ dan besar $\mathrm{V}_{\text {Galih }}$ $\approx 0.99$, sehingga terdapat kesamaan syarat antara $\mathrm{V}_{\text {Galih }}$ dengan koefisien penyusutan $\eta$. Secara lengkap persamaan twist dapat dituliskan seperti persamaan (26) dan persamaan (27). Dengan melakukan aproksimasi, maka Persamaan (26) dan persamaan (27) dapat dibentuk menjadi persamaan (1). Untuk menentukan nilai jejari yarn dapat digunakan

$V_{\text {Galih }}=\frac{2(R-r)}{2 R}=\frac{2(R-r)}{d}$, yaitu dengan mengetahui nilai actual twist $T \approx \frac{1}{V_{\text {Galih }} \pi d}+\frac{n_{\text {rotor }}}{V d}$ dan juga besar kecepatan anguler rotor $\mathrm{n}_{\text {rotor }}$ serta kecepatan delivery yarn $\mathrm{Vd}$ dan juga diameter rotor $d$, maka nilai $\mathrm{V}_{\text {Galih }}$ dapat ditentukan dan jejari yarn yang mempengaruhi koefisien penyusutan yarn dapat diperoleh. Secara umum nilai jejari yarn adalah $r=R-\frac{d V_{G a l i h}}{2}=R-\frac{d \eta}{2}$. Sebagai contoh Vaclav Rohlena, 1975) ${ }^{[3]}$ untuk besar actual twist $1.092,6 \mathrm{~m}^{-1}$ dan twist $1.087 \mathrm{~m}^{-1}$ pada 20 Tex dan 50 $\mathrm{Nm}$ serta rotor speed 30.000/menit dengan $\eta$ $\approx 0.99$ dan $d=60 \mathrm{~mm}$ serta $R=30 \mathrm{~mm}$, maka besar jejari yarn adalah $0,3 \mathrm{~mm}$.

\section{KESIMPULAN}

Twist adalah parameter yang penting untuk mendapatkan jejari yarn serta besar koefisien penyusutan $\eta$. Pada bentuk Z-twist didapatkan bahwa besar actual twist adalah $T=$ $\frac{1}{V_{\text {Galih }} \pi d}+\frac{n_{\text {rotor }}}{V d}\left(1+G_{\text {vidia }}\right) \approx \frac{n_{\text {rotor }}}{V d}$ atau dapat dituliskan dalam bentuk lain yaitu nilai twist $\mathrm{T}$ $=\left(\frac{n_{\text {rotor }}}{V d}+\frac{1}{\pi d}+G_{\text {Vidia }} \frac{1}{\pi d}+G_{\text {Vidia }} \frac{n_{\text {rotor }}}{V d}\right) \approx \frac{n_{\text {rotor }}}{V d}$ 
. Untuk mendapatkan besar koefisien penyusutan $\eta$ $<1$ dan besar nilai $\eta \approx 0.95$, maka dapat dihubungkan dengan penelitian ini menggunakan konstanta $\mathrm{V}_{\text {Galih. }}$ Besar $\mathrm{V}_{\text {Galih }}$ adalah sebesar $V_{\text {Galih }}=\frac{2(R-r)}{2 R}=\frac{2(R-r)}{d}=\eta$ dengan jejari yarn adalah $r=R-\frac{d V_{\text {Galih }}}{2}=R-\frac{d \eta}{2}$

\section{DAFTAR PUSTAKA}

1. Furter, Measurement and significance of yarn twist, Uster Technology AG, Switzerland, 2009

2. Lawrence, Advances in yarn spinning technology, The textile Institute, Cambridge, UK, 2010

3. Rohlena, Vaclav., Open-End Spinning, Elseiver Scientific Publishing Company, New york, 1975

4. Trommer, Gunter., Rotor Spinning, Deutscher fachverlag, Frankfurt, 1995 